\title{
A escrita como desejo
}

\section{Ana Campos}

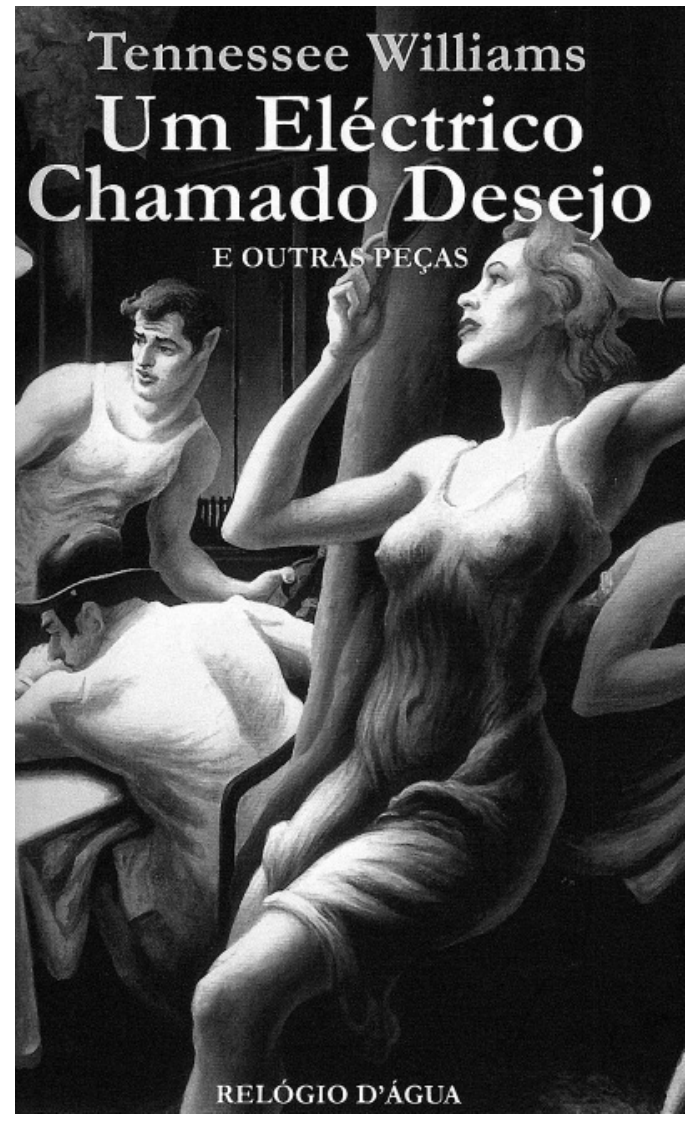

Bem conhecido do público português, Tennessee Williams (de nome próprio Thomas Lanier Williams, 1911-1983) foi já levado à cena, de acordo com os registos da CETbase, mais de trinta vezes em Portugal desde 1957, quando o Teatro Popular de Arte / Companhia de Teatro Maria Della Costa [Brasil] apresentou no palco do Teatro Apolo Rosa tatuada numa encenação de Flaminio Bollini Cerri. Mas, mesmo em Portugal, e apesar desta constante presença em palco, é pelo grande ecrã que o autor norte-americano é mais conhecido, tendo sido transposto para o cinema (e para a televisão) inúmeras vezes, em todo o mundo, mas fundamentalmente em Hollywood. Foi, com efeito, recriado em cinema e em televisão mais de setenta vezes de acordo com os registos do Internet Movie Data Base, nomeado para o Óscar pelo Melhor Argumento por A Streetcar Named Desire (1951) e Baby Doll (1956), e recebeu ainda o Prémio Pulitzer por A Streetcar Named Desire, em 1948, e por Cat on a Hot Tin Roof, em 1955. Apesar de toda esta popularidade, a sua produção dramática tem sido publicada de forma esparsa e fragmentada entre nós.
Tennessee Williams, Um eléctrico chamado desejo e outras peças, tradução de Helena Briga Nogueira, Lisboa, Relógio D’Água Editores, 2009, 357 pp.

As quatro peças que constituem este livro, Gata em telhado de zinco quente (Cat on a Hot Tin Roof, 1955), Subitamente, no Verão passado (Suddenly, Last Summer, 1958), Verão e fumo (Summer and Smoke, 1947) e Um eléctrico chamado desejo (A Streetcar Named Desire, 1947), configuram a maior antologia traduzida da obra dramática do autor publicada em Portugal até hoje, curiosamente coincidindo - no mesmo ano - com a reedição de outra importante antologia de trabalhos de Tennessee Williams, mas desta vez de pequenos contos, intitulada A noite da iguana e outras histórias apresentada por Gore Vidal e publicada pela Assírio \&t Alvim. Esta é também a primeira edição de que há registo de uma tradução em livro, em Portugal, de Gata em telhado de zinco quente, o que só por si revela muito da pertinência da publicação num ano em que foram levadas à cena três peças do autor: Peça para dois, pela Barraca, Jardim zoológico de cristal, pelo Ao Cabo Teatro e ainda Um eléctrico chamado desejo no Teatro Nacional D. Maria II.

Tennessee Williams sublimou na sua obra os fantasmas da sua própria infância e adolescência atormentadas. Sulista, criado no Mississípi, onde nasceu, e no Missouri, onde passou parte da infância e da adolescência, é nesses espaços que constrói o cenário para muitas das suas peças. É também à sua vida que vai retirar inspiração para a concepção recorrente de determinados tipos de personagens. A sua irmã Rose, a quem foi cedo diagnosticada esquizofrenia, foi, com autorização dos pais, sujeita a uma lobotomia que a incapacitou para o resto da vida, facto que Tennessee Williams nunca Ihes perdoou. Rose terá sido a musa de personagens como Catherine Holly de Subitamente, no Verão passado, a quem a tia Violet quer, por meio de uma operação ao cérebro, silenciar o terrivel segredo que ela poderia revelar sobre Sebastian, o filho de Violet. Foi possivelmente também a pessoa por detrás da figura de Blanche DuBois de Um eléctrico chamado desejo. Estas personagens foram imortalizadas no cinema e no nosso imaginário,

respectivamente por Elizabeth Taylor, na adaptação de Joseph L. Mankiewicz (1959), e por Vivien Leigh, na famosa versão de Elia Kazan (1951).

A sua homossexualidade assumida - apesar dos problemas sociais que acarretou -, inspirou sem qualquer dúvida as figuras do alcoólico e atormentado Brick de Cat on a Hot Tin Roof, que, paralelamente ao casamento, cultivava uma relação próxima da homossexualidade com
Ana Campos é professora do ensino secundário e investigadora do Centro de Estudos de Teatro da Faculdade de Letras da Universidade de Lisboa. 
Um eléctico chamado

desejo,

enc. Diogo Infante,

TNDMII, 2010

(Alexandra Lencastre),

fot. Allpio Padilha.

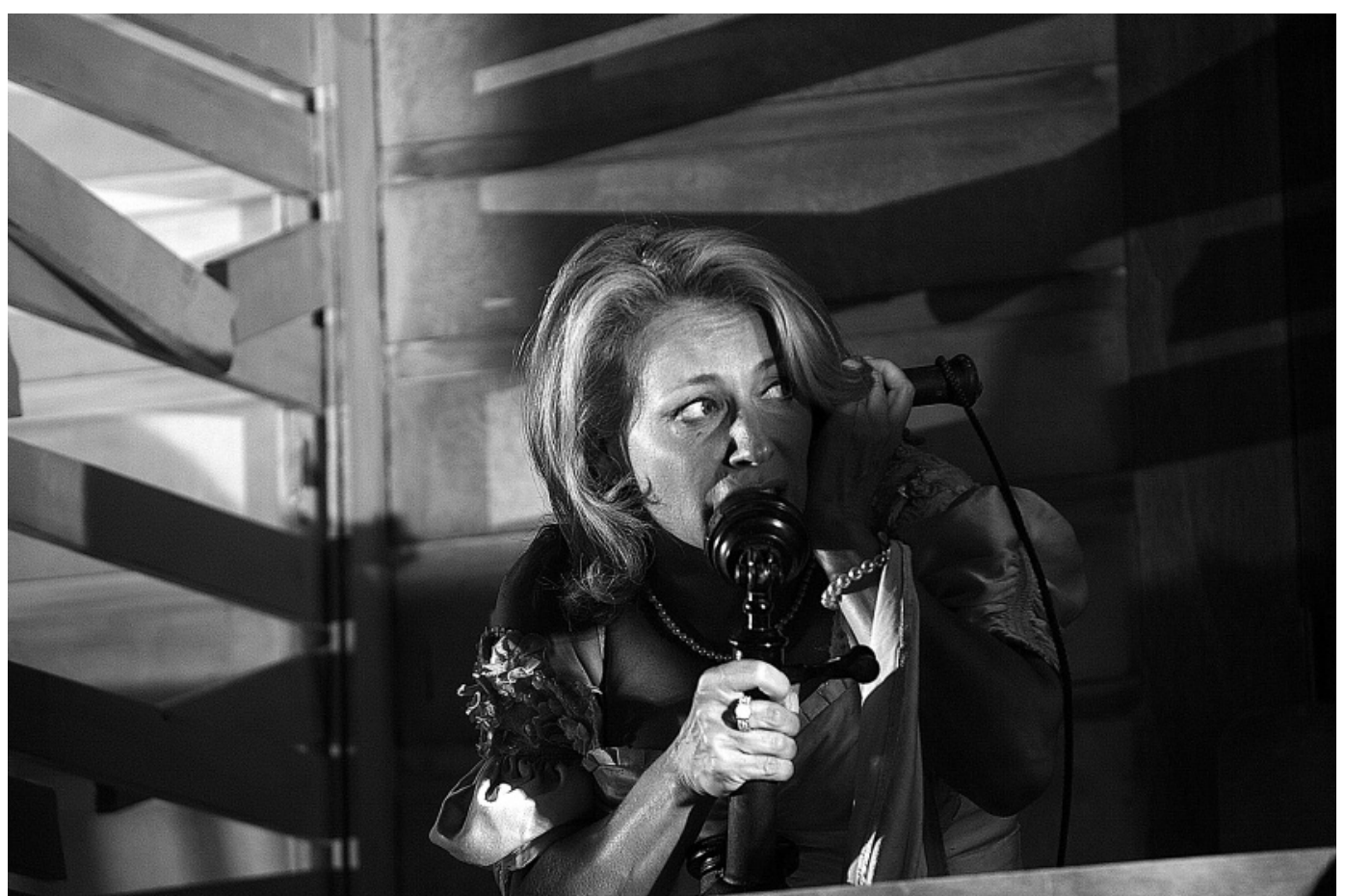

um amigo com quem a sua esposa o trai, e que ficará para sempre na nossa memória pela interpretação de Pau Newman, na adaptação ao cinema de Richard Brooks, em 1958, ainda que nessa versão a temática da homossexualidade seja muito suavizada. 0 mesmo se poderá dizer de Sebastian de Subitamente, no Verão passado, obra produzida depois do início do processo terapêutico que trouxe à luz do dia muitos dos seus tormentos emocionais.

Esta recorrente adaptação ao cinema de obras suas deriva também do enorme sucesso que as peças obtiveram nas primeiras encenações. Cat on a Hot Tin Roof foi levada à cena em 1955, em versão diferente da que foi transposta para o cinema, numa encenação dirigida curiosamente também por Elia Kazan, no Morosco Theatre, na Broadway, recebendo o Prémio Pulitzer, assim como o New York Drama Critics' Circle e o prémio Donaldson. Esta peça foi levada à cena pela companhia do Teatro Monumental, com encenação de António Pedro, em 1959.

Enquanto isso, Suddenly, Last Summer estreou fora da Broadway, na York Playhouse, em conjunto com outra peça, também em um acto, intitulada Something Unspoken garantindo a Anne Meacham o Prémio Obie para a sua interpretação de Catherine. Em 1959, surgirá a versão em filme com Elizabeth Taylor, Katherine Hepburn e Montgomery Clift.

Summer and Smoke, de 1948, intitulada inicialmente Chart of Anatomy, e revista, em 1964, com o nome de Eccentricities of a Nightingale, estreou em 1948, pelo Music Box Theatre, em Nova lorque, mas o seu verdadeiro sucesso veio com a encenação de José Quintero, de 1952 que contou com a interpretação, entre outros, de Geraldine Page no recém-formado Circle in the Square Theatre o qual viria a dar inicio a um movimento off-Broadway. Esta versão foi transposta para o cinema em 1961 por Peter Glenville, e aí Geraldine Page voltou a interpretar a personagem de Alma. Em 1965, a peça é levada à cena pela Companhia Portuguesa de Comediantes, com tradução de Costa Ferreira.

Por fim, A Streetcar Named Desire estreou na Broadway em 1947 e esteve dois anos consecutivos em cena no Ethel Barrymore Theatre numa encenação dirigida por Elia Kazan e contando com a interpretação de Marlon Brando que depois viria a representar novamente Stanley no cinema. Esta peça venceu o prémio Pulitzer para melhor drama, o Donaldson e New York Critics' Circle. Em 1952, a versão para cinema desta peça recebe o New York Film Critics' Circle Award. Será em 1963 que a Companhia Rey ColaçoRobles Monteiro leva este texto à cena com encenação de Henriette Morineau e tradução de António Pedro.

À excepção de Verão e fumo, as peças incluídas nesta antologia são sem dúvida as mais emblemáticas da obra do dramaturgo norte-americano. Parece-me, contudo, que a edição carece de uma nota explicativa dos critérios que presidiram à selecção destes textos, unidos evidentemente pela temática fortíssima do desejo, que Tennessee Williams soube trabalhar como poucos dramaturgos. A edição teria muito a ganhar também com um enquadramento de cada peça e dos textos do autor que antecedem algumas delas. Por exemplo, Gata em telhado de zinco quente é acompanhada de "Uma palavra ao leitor", texto do autor onde este apresenta a sua intenção, mas que surge desprovido não só de data como de qualquer indicação do contexto em que foi originalmente publicado. Também Um eléctrico chamado desejo é precedido por um artigo de Tennessee Williams intitulado "Sobre o sucesso de Um eléctrico chamado desejo", embora aqui seja indicada a sua publicação na secção de teatro do The New York Times, quatro dias antes da estreia desta peça. Nesse texto, o autor reflecte sobre o sucesso - enorme e súbito - que está a viver desde a estreia de The Glass Manegerie e que, de algum modo, parece ultrapassar as suas expectativas e determinar uma urgência de escrita. Todo este material, bastante útil, sê-lo-ia ainda mais se surgisse enquadrado, de forma a 


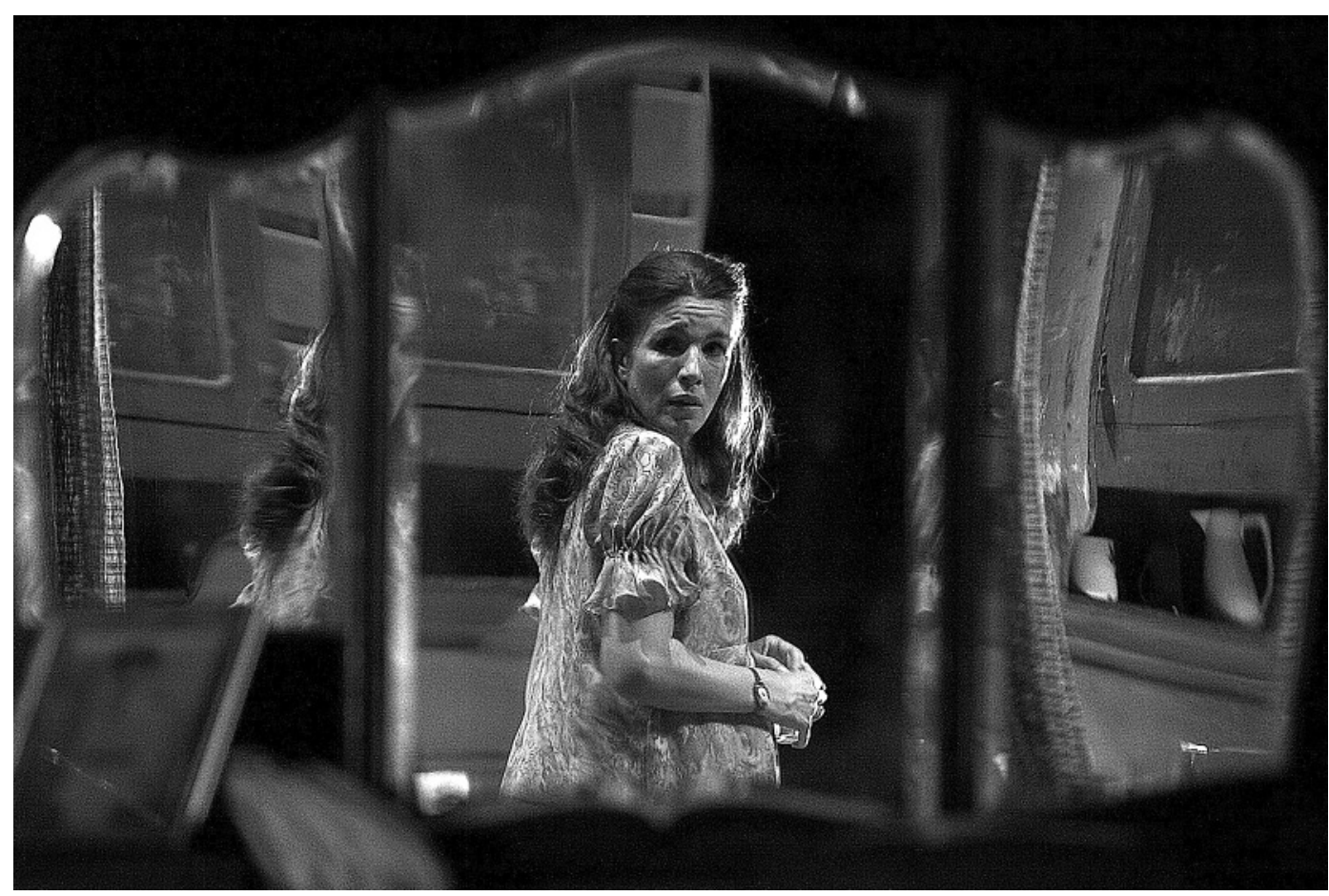

Um eléctico chamado

desejo,

de Tennessee Williams, enc. Diogo Infante, TNDMII, 2010 (Lúcia Moniz), fot. Allpio Padilha.
conferir-Ihe coesão e contextualização histórica. A pertinência desta publicação fica assim aquém da importância que poderia ter pela falta de uma reflexão editorial séria sobre a antologia apresentada.

Centremo-nos, pois, nas diferenças qualitativas desta tradução relativamente às anteriores disponiveis: refirome a Bruscamente, no Verão passado, traduzido em 1964 por Rui Guedes da Silva, e a Fumo de Verão traduzido por Luis de Sttau Monteiro em 1962, já que a única tradução disponivel em lingua portuguesa de A Streetcar Named Desire é brasileira, data de 1976, e é difícil acesso em livro. Como o próprio título indica, a primeira destas traduções assume claramente o facto de ser uma leitura necessariamente subjectiva da peça. De facto, a opção pelos advérbios "subitamente" ou "bruscamente" não é irrelevante: a opção por "bruscamente" implica uma tomada de posição sobre os factos ocorridos naquele Verão, inesperados, é certo, mas de uma brutalidade chocante. Nesta tradução, Rui Guedes da Silva preocupa-se, como vemos, em fornecer ao público português uma versão actual de um texto recente e muito marcante da dramaturgia mundial, fazendo-o preceder da indicação da data da estreia em teatro e respectivo elenco, anotando o facto de a peça não ter sido até então levada à cena em Portugal.

A tradução parece-me surgir assim com um intuito deliberado de propor uma possivel encenação, ao contrário da versão brasileira de Helena Briga Nogueira em que a tradutora parece limitar-se a traduzir sem apresentar qualquer reflexão crítica sobre a obra.

Também a versão de Sttau Monteiro, logo desde a apresentação da temática da obra na contracapa do livro "Drama repassado de tragédia, que põe frente a frente dois seres que se amam de maneiras totalmente opostas - ela idealista e ele sensualmente apaixonado - Fumo de Verão é uma angustiante ilustração de eterno conflito ente a carne e o espírito", propõe assumidamente uma versão do texto original marcada pelo crivo do tradutor, ele próprio um dramaturgo. Tanto assim é que faz preceder a sua proposta por uma nota sua onde analisa a obra do autor norte-americano, afirmando a dado passo:

Há em todas as peças de Tennessee - da Battle of Angels ao Night of the Iguana - dois elementos permanentes que explicam a sua obra e, em grande parte, o próprio teatro americano dos nossos dias: o egoismo feroz das personagens entregues de alma e coração a um pursuit of happiness puramente individual e a constatação, afinal, de que as personagens estão tão longe dessa happiness como o estavam no início da peça." (Monteiro 1962)

Fumo de Verão de Sttau Monteiro é também uma recriação literária do texto original. Nesse texto ainda, Sttau Monteiro apresenta a sua leitura da história, analisa a construção das personagens, questiona as opções do dramaturgo, inscreve os assuntos das questões em debate na América de então, defende a sua concepção de teatro, explicando assim ao leitor o texto que se irá seguir. Esta é portanto uma edição crítica que inclui também as notas do autor para a encenação. Esta breve comparação conduz-nos inevitavelmente à questão essencial: a versão proposta pela Relógio D'Água, ainda que pertinente, muito teria a ganhar se fosse acompanhada por uma real preocupação não apenas em apresentar informação mais apurada, como também em avaliar literariamente os textos inscrevendo-se assim no trilho iniciado pelas traduções precedentes.

\section{Referências bibliográficas}

MONTEIRO, Luis de Sttau (1962), in WILLIAMS (1962).

WILLIAMS, Tennessee (1962), Fumo de Verão, trad. Luis de Sttau Monteiro, Lisboa, Publicações Europa-América.

-- (1964), Bruscamente, no Verão passado, trad. Rui Guedes da Silva. Lisboa, Editorial Presença. 